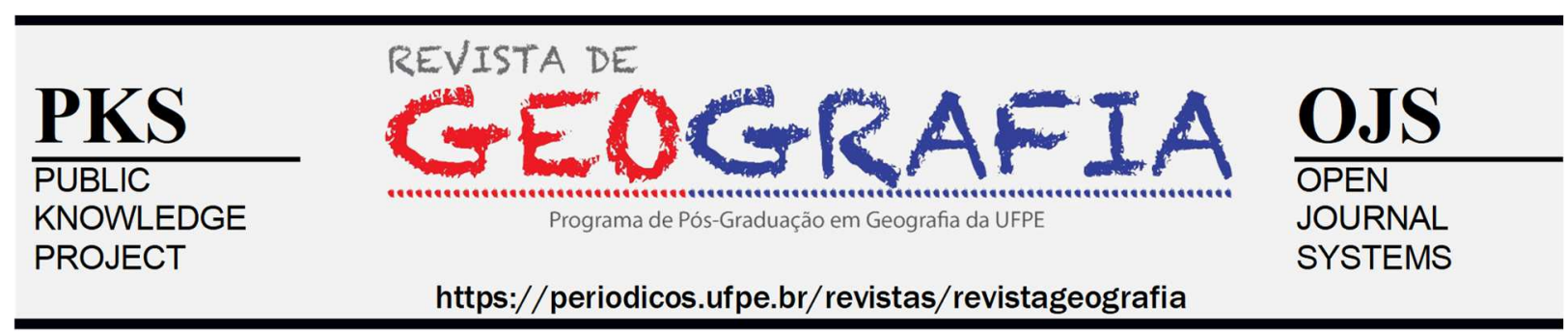

\title{
O USO DO LIVRO DIDÁTICO COMO PRINCIPAL FERRAMENTA NO ENSINO DE GEOGRAFIA DA EDUCAÇÃO DE JOVENS E ADULTOS - EJA
}

\author{
Maia Aparecida da Silva Dias ${ }^{1}$
}

1 Pós Graduanda em Desenvolvimento Sustentável no Semiárido com Ênfase em Recursos Hídricos (DSSERH), do Instituto Federal de Educação Ciência e Tecnologia Baiano, Campus Senhor do Bonfim - BA. E-mail: mariaaparecidadias1.7@gmail.com; ORCID: https://orcid.org/0000-0002-9908-443X

Artigo recebido em 11/06/2020 e aceito em 06/03/2021

\section{RESUMO}

O presente artigo procura discutir acerca da utilização do livro didático de Geografia nas turmas da Educação de Jovens e Adultos - EJA, do Centro Noturno de Educação da Bahia - CENEB, evidenciando a importância do ensino de Geografia para os estudantes da EJA, tendo como objetivo basilar compreender a forma de utilização do livro didático de EJA como principal ferramenta didática das aulas de Geografia. Esta pesquisa foi desenvolvida a partir da experiência da autora no Estágio Supervisionado em Geografia IV, do curso de Licenciatura Plena em Geografia, da Universidade do Estado da Bahia - UNEB, Campus IV. A metodologia utilizada é de abordagem qualitativa de caráter exploratório, a partir do estudo de campo e o levantamento bibliográfico. Foi possível perceber durante o período de regência, que o principal recurso utilizado pelos professores de geografia do CENEB era o livro didático e que esse, nem sempre é suficiente para o ensino dos conteúdos basilares dessa disciplina, assim faz-se necessário que o professor busque continuadamente utilizar outras ferramentas didáticas e interativas, a fim de agregar mais conhecimento a formação dos alunos e as suas aulas, bem como para tornar as aulas de geografia mais atrativas e dinâmicas.

Palavras-chave: Livro didático; Educação de Jovens e Adultos; Estágio Supervisionado em Geografia IV; Centro Noturno de Educação da Bahia.

\section{THE USE OF THE TEACHING BOOK AS A MAIN TOOL IN TEACHING THE GEOGRAPHY OF YOUTH AND ADULT EDUCATION - EJA}

\begin{abstract}
This article seeks to discuss the use of the Geography textbook in the classes of Youth and Adult Education - EJA, of the Centro Noturno de Educação da Bahia - CENEB, highlighting the importance of teaching Geography to EJA students, with the basic objective of understanding how to use the EJA textbook as the main didactic tool in Geography classes. This research was developed based on the experience of the author in the Supervised Internship in Geography IV, of the Full Degree course in Geography, of the University of the State of Bahia - UNEB, Campus IV. The methodology used is an exploratory qualitative approach, based on the field study and the bibliographic survey. It was possible to realize during the regency period that the main resource used by geography teachers at CENEB was the textbook and that this is not always enough to teach the basic contents of this subject, so it is necessary that the teacher continuously seeks to use other didactic and interactive tools to add more knowledge to the training of students and their classes and make the geography classes more attractive and dynamic.
\end{abstract}

Keywords: Textbook; Youth and Adult Education; Supervised Internship in Geography IV; Night Education Center of Bahia. 


\section{INTRODUÇÃO}

Este artigo foi desenvolvido a partir das experiências vivenciadas no Estágio Supervisionado em Geografia IV, do curso de Licenciatura plena em Geografia, da Universidade do Estado da Bahia - UNEB, Campus IV, Jacobina - BA, realizado no Centro Noturno de Educação da Bahia CENEB.

O ensino de Geografia nas turmas da Educação de Jovens e Adultos pode trazer grandes contribuições na formação dos alunos, visto que concederá a oportunidade desses estudantes ampliarem a visão acerca do espaço geográfico, bem como de todas as relações que direta e indiretamente são estabelecidas nele, contribuindo assim para a formação de um cidadão mais consciente frente a suas atitudes, na sociedade em que está inserido e despertando também sua criticidade.

Entende-se que o livro didático no processo de ensino e aprendizagem, pode contribuir de maneira significativa, tanto na atuação do professor em sala de aula, quanto com o aprendizado dos alunos, principalmente por ele ser um dos recursos mais acessíveis aos alunos e professores, pela grande quantidade disponibilizada na escola pública, distribuída gratuitamente para os estudantes.

Nesse sentido este trabalho se torna relevante por procuramos a partir dele, discutir acerca da importância de utilização do livro didático nas turmas de Educação de Jovens e Adultos - EJA e apresentar alguns recursos que podem ser utilizados junto a este, para um maior rendimento das aulas de geografia.

O principal objetivo dessa pesquisa é compreender a forma de utilização do livro didático de EJA como principal ferramenta didática das aulas de geografia, tendo como problemática: de que forma é utilizado o livro didático nas aulas de geografia, como principal ferramenta didática? Procurando discutir também até que ponto o livro didático de EJA pode ser utilizado como único recurso para a realização dessas aulas. Esse questionamento surgiu através do contato da autora com o Centro Noturno de Educação da Bahia - CENEB, durante o período de regência do estágio supervisionado IV, na turma de $1 \% 2^{\circ}$ ano da Educação de Jovens e Adultos, em que foi observado, na etapa inicial do estágio, na qual são realizadas observações das aulas de geografia, dos professores regentes atuantes na instituição, que a maioria dos professores utiliza o livro didático como principal, se não única ferramenta de ensino.

Para desdobramento dessa pesquisa, será discutido acerca da importância do ensino de geografia nas turmas de EJA, tendo em vista que estas são compostas, na maioria dos casos, por um 
público diversificado. Também decorrerá a discussão sobre a utilização do livro didático como principal ferramenta na sala de aula e, posteriormente, serão apresentadas sugestões de recursos e metodologias que podem ser aplicadas para o ensino de geografia.

A metodologia utilizada, portanto, é de caráter qualitativo, buscando a caracterização inicial do problema, identificado a partir da realização do Estágio IV, durante o período das observações e regência no CENEB, bem como o levantamento bibliográfico, visando recuperar o conhecimento científico acerca da utilização dos livros didáticos em turmas de EJA.

\section{O ensino de Geografia em turmas de EJA}

O ensino da geografia é indispensável na formação dos alunos do ensino médio, mais especificamente para as turmas de EJA, que é o objeto desse estudo, pois através dele tem-se a possibilidade de formação de cidadãos mais críticos e conscientes, a partir das discussões efetivadas em sala de aula, assim como das análises e relações feitas pelo próprio aluno, da sua realidade, com o que é discutido em classe, sendo mediadas pelo professor.

Compreende-se que os estudantes das turmas de EJA, mais especificamente do CENEB, são um público bem diversificado, pois possui diversas faixas etárias, sendo que boa parte deles, se não todos, já repetiram a mesma série algumas vezes. Também praticamente todos os estudantes trabalham durante o dia, assim, na maioria dos casos, não há tempo para realizarem atividade extraclasse ou ainda, estudarem algum conteúdo discutido em sala de aula, no entanto esses alunos demonstram interesse em dar continuidade aos estudos, a fim de conseguir um crescimento pessoal e profissional, bem como conceder uma melhor qualidade de vida para suas famílias.

No ensino de geografia, o professor não pode ignorar o conhecimento empírico e o que foi adquirido pelos alunos ao longo da vida, suas experiências, visto que todos possuem uma carga de

conhecimento. É importante então que o professor procure continuamente estabelecer relações do conteúdo discutido na sala de aula com o cotidiano dos alunos, para que assim, esses estudantes consigam abstrair e aplicar os conteúdos aprendidos em classe, na sua realidade.

É necessário que o professor de geografia busque sempre metodologias que atraiam os estudantes e os envolvam em suas aulas, a fim de haver uma melhor compreensão de mundo, da sociedade na qual ele está inserido e um reconhecimento dos diversos grupos existentes, muitos dos quais esses estudantes estão direta ou indiretamente ligados, buscando a valorização de suas identidades. 
Dessa forma é preciso que haja também um incentivo por parte do educador para que os estudantes dêem continuidade aos estudos, pois, na maioria das vezes, esses alunos não têm expectativa de prosseguir com seu processo formativo, assim, cabe ao professor, mostrar as diversas possibilidades que esse aluno tem, tanto para concluir o ensino médio como prosseguir com os estudos e até ingressar no ensino superior.

É valido ressaltar ainda da importância de haver uma formação continuada dos professores, para que estes estejam à pá das discussões sobre o público de EJA e que, tenham suporte tanto de coordenadores, diretores, como também pesquisadores e de todos os agentes escolares.

\section{A utilização do livro didático nas aulas de geografia como principal ferramenta}

Utilizado hoje em praticamente todas as escolas do Brasil, o livro didático pode ser considerado o recurso mais acessível aos alunos e professores, principalmente de escolas públicas. Este recurso traz grandes contribuições ao processo de ensino e aprendizagem, pois concede aos docentes a oportunidade de utilizá-lo nas aulas, na realização de atividades em classe, em discussões de determinados conteúdos e ainda como fonte de pesquisa pelos alunos.

É necessário então reconhecer a importância do acesso a um livro didático de boa qualidade, visto que se este não for acessível a todos, ou ainda, for de difícil compreensão para os alunos, comprometerá o desenvolvimento das aulas. Acerca do livro didático Frison, et. al. afirmam que:

\footnotetext{
Atualmente, os livros didáticos representam à principal, senão a única fonte de trabalho como material impresso na sala de aula, em muitas escolas da rede pública de ensino, tornando-se um recurso básico para o aluno e para o professor, no processo ensinoaprendizagem (FRISON, et. al. 2009, p. 4).
}

Desse modo, é preferível que tanto professores como alunos, tenham acesso ao livro didático, visto que, quando bem utilizado, o mesmo trará muitas informações e conteúdos necessários à formação do indivíduo, além de que, como afirmou Frison, muitas vezes ele é a única fonte de trabalho acessível aos professores. Além disso, em posse do livro, o aluno tem contato com esse instrumento didático também em outros momentos do seu cotidiano, que não sejam exclusivamente durante as aulas, assim, de acordo com Copatti.

Participando da vida cotidiana para além da escola, o livro didático geralmente traz presente várias propostas em que os estudantes são instruídos a realizar pesquisas, interagir com determinados grupos, investigar espaços para observar elementos naturais ou a 
intervenção humana presente nele. Entretanto, estas são propostas que podem ser aprimoradas e direcionadas para situações locais. Ou seja, adaptadas ao contexto em que o estudante vive (COPATTI, 2017a, p. 90).

Nesse sentido, quando o livro apresenta propostas que estimulam o aluno a interagir e investigar determinados elementos no ambiente em que ele está inserido, esse estudante passa a fazer uso desse instrumento de ensino não apenas em sala de aula, mas também nas atividades extraclasse.

É preciso reconhecer também a importância da presença do livro no ambiente escolar, como material que auxilia o ensino e aprendizagem de alunos e docentes das escolas públicas brasileiras, pois apesar dos diversos recursos que os professores tem acesso hoje, o livro didático ainda permanece sendo muito utilizado em classe.

Este recurso é considerado um suporte ao ensino de geografia, e se mantém presente em sala de aula mesmo com inúmeros outros materiais e recursos disponíveis aos professores; por isso precisa ser compreendido para além das possibilidades que disponibiliza, mas considerando, também, o modo como os professores estabelecem vínculos com ele no cotidiano (COPATTI, 2017a, p. 75).

Diante do que foi posto por Copatti, é possível observar que mesmo com o acesso pelos professores a outros matérias e recursos como salas de multimídia, data-show, acesso a fotos e vídeos nas aulas, ambientes virtuais, entre outros, o livro didático continua contribuindo não apenas com o ensino de geografia, mas das diversas outras ciências, presentes na formação dos alunos da educação básica, por isso, é importante que os professores explorem ao máximo as possibilidades de utilização dele.

Essa mesma autora, em seu trabalho "Professor de geografia e livro didático: interações na prática docente", faz a analogia do livro didático a um "manual”, utilizado pelo professor.

O Livro didático passa a ser considerado como a própria aula do professor, visto que dele se utiliza como um manual a ser seguido. Nesse contexto, o Livro didático é utilizado como "manual" que conduz o professor, ao invés de ocorrer o contrário, ou seja, o professor conduzir seu trabalho e utilizar-se do Livro didático como uma fonte de informação (COPATTI, 2017b, p. 3-4).

Diante dessa afirmação da autora, observa-se que o livro didático algumas vezes deixa de ser um suporte ao trabalho do professor e passa a servir como um "manual", contendo propostas de trabalho prontas, que direcionam o professor e, inúmeras vezes, não são adaptadas ao planejamento 
da escola, nem ao contexto específico em que esse profissional atua. Nessa concepção, o professor serviria apenas como um repassador das informações contidas no livro didático.

À medida que o livro é utilizado como única ferramenta nas aulas de geografia, em que o professor apenas reproduz o conteúdo apresentado nele, o processo de ensino e aprendizagem fica prejudicado, pois o livro passa de subsídio, a instrumento basilar, que determina os conteúdos que serão estudados durante todo o ano letivo, limitando frequentemente, a compreensão dos conteúdos pelos estudantes por não conseguirem estabelecer uma relação com suas vivências.

É possível observar ainda em determinados livros que, por não serem submetidos a uma revisão minuciosa durante o processo de escolha, ou ainda, devido os autores não possuírem formação nas áreas de conhecimento específicas desses materiais, haja assim falhas nos conceitos apresentados, acarretando também numa visão distorcida de determinados conteúdos.

Acerca dessa problemática, Santos e Albuquerque, 2014, apresentam uma análise de livros didáticos, nas quais perceberam que, em três edições da coleção Projeto Araribá: Geografia, 2007, do $6^{\circ}$ ao $9^{\circ}$ ano, todos os exemplares analisados possuíam autores diferentes em cada edição, além disso, nenhum dos autores tinha formação em geografia. É perceptível também a predominância do conteúdo de geografia humana em todos os exemplares, em relação aos conteúdos de geografia física (SANTOS E ALBUQUERQUE, 2014).

Diante disso, se o professor não utilizar outras fontes de pesquisa em situações semelhantes, o ensino de geografia deixará lacunas, visto que o estudante terá pouco contato com o ensino de geografia física, sendo que essas duas vertentes, tanto a geografia humana como a geografia física, são interdependentes e precisam ser trabalhadas em conjunto, para que não gere deficiência no processo formativo dos alunos. Além do que, quando o profissional não possui uma formação na área específica do livro didático que está produzindo, há a possibilidade de que ele cometa erros conceituais, generalizações e ainda não contemple discussões essenciais a ciência específica a ser estudada.

Uma problemática que pode ser encontrada no uso exclusivo do livro didático é a estrutura do livro, pois por se tratar de um único exemplar utilizado durante todo o ano, seus conteúdos precisam ser resumidos, para que contemple várias propostas de discussões, dessa forma, algumas temáticas essenciais são tratadas de forma superficial, então se o professor utiliza esse único recurso e não estimular os alunos a buscarem outras fontes de pesquisa, a produção de conhecimento estará limitada ao conteúdo apresentado no livro. É válido apresentar ainda outro impasse encontrado, inclusive no CENEB, que é a pouca quantidade de exemplares e até ausência dos livros didáticos, 
dessa maneira o alcance do aluno a determinados conteúdos, se o mesmo não tiver acesso a outras fontes de pesquisa, fica inviável.

Desta forma reconhecemos a grande contribuição do livro didático para o ensino de geografia, desde que haja um cuidado na sua escolha, para que o mesmo esteja adequado ao público

destinado, que não possua erros conceituais e abordagens distorcidas da realidade e não seja colocado como fundamental ditador dos caminhos a serem seguidos durante as aulas e no decorrer do ano.

\section{Possibilidades e sugestões de recursos e metodologias a serem utilizadas}

No estágio de regência busca-se continuamente a aplicação de metodologias e a utilização de ferramentas, a fim de tornar as aulas mais atraentes e dinâmicas, assim, nesse período, foi possível utilizar diversos recursos durante as aulas, além do livro didático, dessa forma procuramos apresentar possibilidades para um desenvolvimento mais significativo das aulas de geografia, a partir da descrição das aplicações dessas práticas na turma escolhida para a regência.

$\mathrm{O}$ estágio foi realizado na turma $\mathrm{C}$ de $1 \% 2^{\circ}$ ano de EJA, como já citado anteriormente e nosso público tinha a faixa etária entre 18 e 35 anos, com 50 alunos matriculados e cerca de 35 frequentes, então as atividades deveriam ser adaptadas, a fim de atender a esse público variado.

O tema central da unidade foi "O capitalismo e a construção do espaço: pobrezas e riquezas no espaço urbano". Nas aulas em que foram discutidos sobre Multinacionais e Transnacionais, empresa matriz e filial, foi apresentado os conceitos de ambos no quadro. Posteriormente solicitouse aos alunos que levassem na próxima aula embalagens de produtos produzidos por multinacionais, em que a matriz era de algum país que não fosse o Brasil, mas que tivesse sua filial em algum estado aqui do país, essas informações seriam colhidas nas próprias embalagens dos produtos e a partir de pesquisas da internet, além do conhecimento prévio sobre essas multinacionais que os estudantes já possuíam. Em equipe os alunos colariam no centro do cartaz um mapa mundi e a sua volta, as embalagens, o resultado dessa atividade pode ser conferida na figura a seguir:

Figura 01 - Produção de cartaz em grupo 


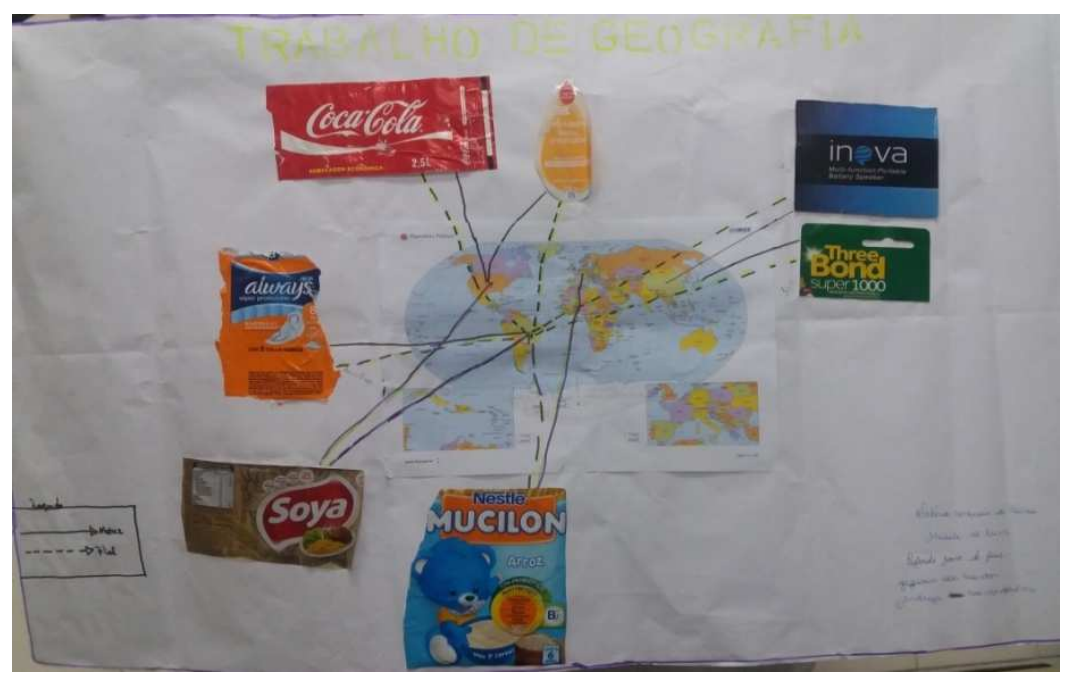

FONTE: A autora, 2017.

Observamos na imagem que os países onde estão instaladas as empresas matrizes são identificados com uma linha contínua, já os estados das empresas filiais foram identificados com uma linha pontilhada. Essa atividade foi bastante produtiva, visto que os alunos estavam com grande dificuldade para compreenderem a diferença de matriz e filial e após o trabalho, foi possível perceber que essas dúvidas foram sanadas.

Percebemos então que a relação entre os conteúdos, atividades realizadas e os instrumentos utilizados durante a aula levam o aluno a aprendizagem, pois conforme Junior, 2010:

\footnotetext{
Sem uma articulação bem-organizada entre conteúdo e forma, a utilização de retroprojetores e da internet pode não contribuir significativamente para que o aluno passe de um conhecimento menor ou empírico para um conhecimento melhorado e sistematizado. [...] Há bons professores que mesmo utilizando a própria voz, o giz e o quadro-negro, conseguem envolver os alunos em atividades produtivas na construção do saber (2010, p. 78-79).
}

Dado isso, compreende-se que uma aula produtiva não dependerá apenas dos instrumentos utilizados pelo professor, mas da articulação entre as explicações e recursos, bem como a participação ativa de todos os estudantes durante a mesma.

Uma estratégia possível para melhor desenvolvimento das aulas também são os recursos de multimídia, que foram utilizados durante a regência como recursos auxiliares no acesso a imagens e vídeos sobre os diferentes modos de produção, do início da sociedade capitalista aos dias atuais, assim foi possível apresentar as transformações ocorridas ao longo do tempo para facilitar a compreensão dos alunos. 
Segundo Sá e Vieira (2010, p. 104) “O vídeo é um recurso importante para fixar melhor o conteúdo durante a aprendizagem dos alunos. As imagens ou cenas apresentadas através do vídeo são importantes, principalmente para visualização da paisagem”, então, concordando com Sá e Vieira, o uso de vídeos é uma ferramenta muito útil durante as discussões, ajudando os estudantes na compreensão da temática de forma interativa. Desse modo, é necessária a busca contínua pelos vários recursos disponíveis, para que os estudantes tenham conhecimento e acesso a estes, conseguindo aprender de forma mais clara e dinâmica os conteúdos apresentados.

Outra estratégia que pode ser utilizada é o uso da música, pois esta, quando bem escolhida, consegue prender a atenção dos alunos e facilitar a compreensão, à medida que conseguem fazer relação dela com o os conceitos apresentados. Podemos citar como exemplo de uma aula realizada na turma de EJA sobre países subdesenvolvidos, em que após a aula expositiva, durante a discussão sobre a temática, foi utilizada a música "Canção do Subdesenvolvimento" que tem composição de Carlos Lyra \& Chico de Assis. Após ser ouvida na sala, foi aberto espaço para o debate. Essa canção aborda os principais aspectos do país subdesenvolvido, logo, ao passo que os alunos iam lendo trechos da canção, comentavam e se posicionavam a respeito da letra. Foi uma atividade muito produtiva, visto que contou com a participação da maioria da sala e houve um grande envolvimento dos estudantes.

É válido falar ainda do uso de charges, que apresentam uma forma irônica de tratar determinadas temáticas. Elas foram utilizadas na aula sobre países ricos e pobres, na qual os alunos foram divididos em equipes e receberam charges diferentes para discutirem entre si e, posteriormente, apresentarem para a turma, promovendo também uma maior interação entre os discentes. A partir da aplicação dessas atividades percebeu-se que é importante a realização dos trabalhos em grupo, pois conforme Sá e Vieira:

\footnotetext{
Os trabalhos em grupo precisam ser valorizados não apenas como alternativa à aula expositiva, mas, principalmente, por permitirem ao aluno o desenvolvimento da socialização, a construção das qualidades do ser social: responsabilidade, colaboração, participação, respeito à opinião do outro, atenção como ouvinte etc. (2010, p. 113).
}

Nesse sentido, de acordo com esses autores, as atividades em grupo podem despertar no aluno uma motivação para que ele se posicione acerca de determinada discussão, como também o respeito a opinião do outro, promovendo ainda uma socialização entre os estudantes, a partir de um estudo coletivo, que permite reflexões e discussões até se chegar a um consenso, para ser posteriormente apresentada a turma. 
É importante utilizar diferentes estratégias para aproximar-se do aluno, conforme Moran, Masetto e Behrens “[...] Chegar ao aluno por todos os caminhos possíveis: pela experiência, pela imagem, pelo som, pela representação (dramatizações, simulações), pela multimídia, pela interação on-line e off-line.” (2011, p. 61). Buscando caminhos mais próximos e interessantes para o estudante e permitindo que este tenha desejo de aprender, não importando o recurso utilizado, mais a forma como o mesmo pode ser usado e relacionado com a realidade do aluno, "ter consciência de que esses recursos não garantem, isoladamente, a dinamização da aula" (NISHIDA e PUERTA, 2010, p. 125), são apenas recursos e necessitam da mediação do professor.

Portanto é importante que o professor compreenda a necessidade da utilização de diversos recursos em classe, mas que estes, isoladamente, não garantem a dinamicidade das aulas, isso dependerá do engajamento e dedicação tanto do professor como dos estudantes, bem como que o docente busque continuamente novas estratégias para dinamizar suas aulas a fim de contribuir com a aprendizagem e o crescimento dos seus alunos.

\section{Considerações finais}

O ensino de Geografia nas turmas de EJA certamente necessita de muito engajamento de todo corpo escolar. Para que haja compreensão de conteúdos e formação de um cidadão consciente e crítico, com uma visão diferenciada de mundo, faz-se necessária também uma motivação aos alunos, por parte do professor, visto que muitas vezes esses estudantes buscam apenas a conclusão do ensino médio para conseguirem uma certificação.

O livro didático sem dúvidas contribui muito com as aulas de Geografia, principalmente por ser um recurso de acesso gratuito aos alunos e professores. No entanto, quando usado como único recurso didático e escolhido sem uma análise prévia e rigorosa, ele consegue interferir na formação do estudante, à medida que pode apresentar erros conceituais ou conteúdos muito resumidos, impedido algumas vezes o estudo de temáticas essenciais no ensino de geografia.

Há diversos recursos e muitas possibilidades de dinamizar as aulas de geografia, como o uso de vídeos, imagens, músicas, trabalhos em equipe, exposições, entre diversos outros, então cabe ao professor buscar continuamente enriquecer suas aulas, a partir da utilização das várias ferramentas disponíveis, não unicamente o livro didático, a fim de promover uma aprendizagem significativa de seus alunos. 


\section{REFERÊNCIAS}

COPATI, Carina. Livro didático de geografia: da produção ao uso em sala de aula. Élisée. Rev. Geo. UEG - Porangatu, v.6, n.2, 2017 ${ }^{\mathrm{a}}$ p.74-93. Disponível em: <https://www.revista.ueg.br/index.php/elisee/article/view/6634>Acesso em: 18/02/2021.

\section{COPATI, Carina. PROFESSOR DE GEOGRAFIA E LIVRO DIDÁTICO: INTERAÇÕES NA} PRÁTICA DOCENTE. XXII Jornada de Pesquisa UNIJUÍ. 2017b, p. 1-6. Disponível em:<https://webcache.googleusercontent.com/search?q=cache:7k94IKhWGt0J:https://publicacoese ventos.unijui.edu.br/index.php/salaoconhecimento/article/view/7748/6485+\&cd=1\&hl=ptBR\&ct=clnk\&gl=br> Acesso em: 18/02/2021.

FRISON, Marli Dallagnol; et. al. Livro didático como instrumento de apoio para construção de propostas de ensino de ciências naturais. Florianópolis: VII ENPEC-(Encontro nacional de pesquisa em Educação em Ciência). 2009. Disponível em: http://posgrad.fae.ufmg.br/posgrad/viienpec/pdfs/425.pdf. Acesso em: 04/08/2017.

JUNIOR, José Aquino. O aluno, o professor e a escola. In: PASSINI, E. Y; PASSINI, R; MALYSZ. S. T. (Orgs). Prática de ensino de geografia e estágio supervisionado. São Paulo: Contexto, 2010.p. 78-85.

MORAN, José Manoel; MASETTO, Marcos T; BEHRENS, Marilda Aparecida. Novas tecnologias e mediação pedagógica. 19ed. Campinas: Papirus, 2011.

NISHIDA, Paulo Roberto. PUERTA, Lorena Lucas. Multimídia na escola: formando o cidadão numa "cibersociedade". In: PASSINI, E. Y; PASSINI, R; MALYSZ. S. T. (Orgs). Prática de ensino de geografia e estágio supervisionado. São Paulo: Contexto, 2007.p. 124-131.

SÁ, Medson Gomes de. VIEIRA, Carlos Eduardo. Recursos didáticos: do quadro-negro ao projetor, o que muda? In: PASSINI, E. Y; PASSINI, R; MALYSZ. S. T. (Orgs). Prática de ensino de geografia e estágio supervisionado. São Paulo: Contexto, 2007.p. 101-116.

SANTOS, Vanda Maria Andrade dos; ALBUQUERQUE, Adorea Rebelo da Cunha. O uso do livro didático como instrumento pedagógico para o ensino de Geografia. Estação Científica (UNIFAP). Macapá, v. 4, n. 1, 2014, p. 63-77. Disponível em: https://periodicos.unifap.br/index.php/estacao/article/view/1314 Acesso em: 18/02/2021. 